\title{
ErbB inhibitors ameliorate behavioral impairments of an animal model for schizophrenia: implication of their dopamine-modulatory actions
}

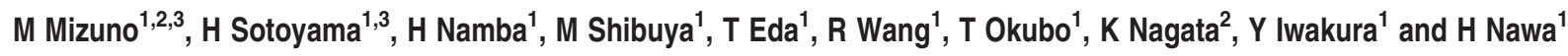

Ligands for ErbB receptors, including epidermal growth factor (EGF) and neuregulin-1, have a neurotrophic activity on midbrain dopaminergic neurons and are implicated in the pathophysiology of schizophrenia. Although ErbB kinase inhibitors ameliorate behavioral deficits of the schizophrenia model that was established by hippocampal lesioning of rat pups, the antipsychotic action of ErbB kinase inhibitors and its general applicability to other models are not fully characterized. Using a different animal model, here, we examined whether and how ErbB kinase inhibitors ameliorate the behavioral endophenotypes relevant to schizophrenia. The animal model for schizophrenia was prepared by exposing neonatal rats to the cytokine EGF. Intraventricular infusion of the ErbB1 inhibitors ZD1839 and PD153035 in these animals ameliorated the deficits in startle response and prepulse inhibition in a dose-dependent manner. The deficits of latent inhibition of fear learning were also alleviated by ZD1839 with its limited effects on body weight gain or locomotor activity. ZD1839 infusion also decreased the busting activity of nigral dopamine (DA) neurons and reduced pallidal DA metabolism, a result that mimics the anti-dopaminergic profile of risperidone and haloperidol in this brain region. ErbB inhibitors appear to have anti-dopaminergic actions to alleviate some of the behavioral deficits common to animal models for schizophrenia.

Translational Psychiatry (2013) 3, e252; doi:10.1038/tp.2013.29; published online 30 April 2013

\section{Introduction}

The ErbB family of receptor tyrosine kinases consists of four members; ErbB1-4 subunits form homo- or hetero-dimer complexes to transduce their signals. Ligands for ErbB receptors are members of the molecular superfamilies represented by epidermal growth factor (EGF) and neuregulins, and are implicated in the etiology or pathology of schizophrenia. ${ }^{1,2}$ Among the ErbB receptors, both ErbB1 and ErbB4 are enriched in midbrain dopaminergic neurons $\mathrm{s}^{3-5}$ and regulate dopamine (DA) function and development. ${ }^{6-11}$ Indeed, transgenic mice overexpressing neuregulin-1 or lacking ErbB receptors exhibit deficits in the dopaminergic system or in DA-associated behavioral traits. ${ }^{2,10,12-15}$ These observations raise the hypothesis that abnormal ErbB signaling might be responsible for dopaminergic impairments in the neuropathology of schizophrenia or in behavioral deficits of its animal models. ${ }^{16-18}$ The expression of ErbB1 and ErbB4 in nigral dopaminergic neurons favors the direct actions of ErbB ligands on this cell population. ${ }^{5}$ For example, brain infusion of EGF or neuregulin-1 triggers DA release and metabolism, and provokes DA-associated behaviors in rats. ${ }^{7,8}$ Conversely, the pharmacological manipulation of dopaminergic neurotransmission alters ErbB1 signaling in the brain. ${ }^{19,20}$ This argument is supported by previous postmortem studies on human brain diseases; the expression of ErbB1 and its ligand are diminished in patients with Parkinson's disease. ${ }^{21}$ Conversely, the upregulation of ErbB1 and ErbB4 expression is found in the forebrain of schizophrenia patients. ${ }^{1,22}$ Despite the neuropathological implication of ErbB signaling in the brain diseases involving dopaminergic dysfunction, ${ }^{23}$ the therapeutic potential of ErbB modulators (activators and inhibitors) remains to be explored.

Recently, we found that ErbB kinase inhibitors ameliorate some of behavioral deficits in the animal models for schizophrenia that were established by neonatal hippocampal lesioning and methamphetamine. ${ }^{24-26}$ These findings suggest that the pharmacological blockade of ErbB1 or other ErbB receptors may have general benefits for the treatment of behavioral impairments relevant to schizophrenia endophenotypes. However, it is unknown whether the observed actions of ErbB kinase inhibitors target the DA system and whether their effects are universal to other animal models. To address these questions, we prepared a schizophrenia model by treating rat pups with the cytokine EGF, which results in various behavioral abnormalities. ${ }^{6,27}$ Using this animal model, we explored the pharmacological actions of two quinazoline derivatives targeting ErbB1 (ZD1839) or ErbB1-4 (PD153035), ${ }^{28,29}$ and compared their potency in sensorimotor gating. We also monitored the unit activity of nigral dopaminergic neurons and brain DA metabolism in this animal model

\footnotetext{
${ }^{1}$ Department of Molecular Neurobiology, Brain Research Institute, Niigata University, Niigata, Japan and ${ }^{2}$ Institute for Developmental Research, Aichi Human Service Center, Kasugai, Aichi, Japan

Correspondence: Professor H Nawa, Department of Molecular Biology, Brain Research Institute, Niigata University, Asahimachi-dori 1-757, Niigata 951-8585, Japan. E-mail: hnawa@bri.niigata-u.ac.jp

${ }^{3}$ These authors contributed equally to this work.

Keywords: dopamine; EGF; ErbB; globus pallidus; schizophrenia

Received 24 September 2012; revised 9 March 2013; accepted 15 March 2013
} 
after receiving one of the ErbB inhibitors. The pharmacological profile of the antipsychotic actions of ZD1839 was compared with that of conventional antipsychoticshaloperidol and risperidone.

\section{Materials and methods}

Subjects. Male Sprague-Dawley rats (postnatal day (PND) 2) with dams were purchased from SLC (Hamamatsu, Japan). Litters were born on PND 1 and culled to 10 male pups with their dam by the vender. Rats (8-10 pups plus their dam or 3-4 rats after weaning) were housed in polypropylene cages ( $58 \mathrm{~cm}$ length $\times 28 \mathrm{~cm}$ width $\times 24 \mathrm{~cm}$ height) and given free access to food and water. The cages were kept in a temperature-controlled colony room $\left(22.0 \pm 1.0^{\circ} \mathrm{C}\right)$ and maintained under a 12-h light-dark cycle (0700 on-1900 off). We used seven independent cohorts of neonatal rats treated with EGF or cytochrome C (control protein; total $n=263$ ). All of the animal experiments described here were approved by the Animal Use and Care Committee of Niigata University and performed in accordance with the Guiding Principles for the Care and Use of Laboratory Animals $(\mathrm{NIH}$, USA). All efforts were made to minimize both the suffering and number of animals used in this study.

Neonatal EGF treatment. Recombinant human EGF ( $0.875 \mathrm{mg} \mathrm{kg}^{-1}$ of body weight; Higeta Shoyu, Chiba, Japan) was dissolved in saline and administered subcutaneously, at the nape of the neck, to half of animals in each litter. This occurred daily from PNDs 2-10. Littermates received the same volume of cytochrome $\mathrm{C}$ and served as controls for all analyses. $^{6}$

Drug administration. After confirming deep anesthesia with sodium pentobarbital (50 $\mathrm{mg} \mathrm{kg}^{-1}$ via intraperitoneal (i.p.) injection (Dainippon-Sumitomo Pharmaceutical, Osaka, Japan)), we secured each rat (PND 54-60) to a stereotaxic apparatus (Narishige, Tokyo, Japan). ${ }^{8}$ We exposed the skull, drilled a hole and implanted a 30-G cannula (Terumo, Tokyo, Japan) into the right side of the lateral ventricle $(0.3 \mathrm{~mm}$ posterior and $1.2 \mathrm{~mm}$ right lateral measured from the bregma, $4.5 \mathrm{~mm}$ below the dura) or into both hemispheres of globus pallidus $(1.0 \mathrm{~mm}$ posterior and $3.2 \mathrm{~mm}$ lateral measured from the bregma, $6.0 \mathrm{~mm}$ below the dura). The cannula was glued to the skull and connected to an Alzet osmotic minipump $\left(0.5 \mu \mathrm{lh}^{-1}\right.$, model 2002; Alza, Palo Alto, CA, USA). The minipump was filled with PD153035 (1.0, 0.1 or $\left.0.01 \mathrm{mg} \mathrm{ml}^{-1}\right)$, ZD1839 $\left(1.0,0.2,0.1\right.$ or $0.01 \mathrm{mg} \mathrm{ml}^{-1}$ ) or $10-20 \%$ dimethyl sulfoxide (DMSO) alone (vehicle). The scalp incision was closed with surgical staples and treated with Cefmetazon, a topical antiseptic (50 mg per day, Sankyo Pharmaceuticals, Tokyo, Japan). We confirmed the position of the cannula after completion of the behavioral tests. The ErbB1 inhibitors, PD153035 (4-(3-bromophenylamine)-6,7dimethoxy-quinazoline; Calbiochem, San Deigo, CA, USA) and ZD1839 (gefitinib; 4-(3-chloro-4-fluorophenylamine)-7methoxy- 6(3-(4-morpholinyl)-quinazoline), AstraZeneca Pharmaceuticals, Osaka, Japan), were dissolved in DMSO, diluted with saline and added to an osmotic minipump.
Alternatively, rats were subchronically treated with conventional antipsychotics: haloperidol or risperidone for 14 days. Haloperidol (Wako Pure Chemical, Tokyo, Japan) was dissolved in sodium acetate buffer $\left(0.15 \mathrm{mg} \mathrm{ml}^{-1}, \mathrm{pH} 5.5\right)$. Risperidone (Janssen Pharmaceuticals, Tokyo, Japan) was obtained as Rispadal $1 \mathrm{mg} \mathrm{ml}^{-1}$ oral solution. Haloperidol (0.3 $\mathrm{mg} \mathrm{kg}^{-1}$ per day) and risperidone $\left(1.0 \mathrm{mg} \mathrm{kg}^{-1}\right.$ per day) were orally administered after PND 56 with the aid of an oral zonde for rats (Natume Seisakusho, Tokyo, Japan).

Schedule of behavioral testing, drug treatment and dissection. Before the minipump was depleted on ErbB inhibitors (14 days after surgery), rats were subjected to behavioral tests after a recovery period of at least 7 days in length following minipump implantation. To avoid interactions between the independent behavioral tests, rats were subjected to the tests with an interval of more than 2 days in order of increasing stress: locomotor activity test, social interaction and acoustic startle test. Independent sets of EGF rats were allocated to contextual fear conditioning. The rats that received the ErbB inhibitors were dissected before the drugs were depleted from the pump.

Enzyme immunoassay for phosphorylated ErbB1 protein. For determination of phosphorylation levels of ErbB1 ( $p Y 1173$ ), brain tissue was homogenized in 10 volumes of homogenization buffer provided with an enzyme immunoassay kit (Biosource TM; Invitrogen, Camarillo, CA, USA). Brain homogenates were centrifuged at $14,000 \mathrm{~g}$ for $30 \mathrm{~min}$ at $4{ }^{\circ} \mathrm{C}$ and immediately subjected to the two-site enzyme immunoassay. The protein concentrations in the samples were determined using a Micro BCA kit (Pierce, Rockland, IL, USA) with bovine serum albumin as a standard. Using the cell lysate from EGF-stimulated A431 cells as a standard, the immunoassay kit for phosphorylated ErbB1 had a minimum dynamic range of at least 100 -fold covering concentrations of 1-100 U per well. The average of two measurements per sample was normalized based on the protein concentration. The specificity of ELISA for phosphorylated ErbB1 was described previously. ${ }^{30}$

Immunoblotting for dopaminergic markers. Whole brains were taken from more than 10 rats in each experimental group and sliced into $1-\mathrm{mm}$ thick coronal sections. The exterior globus pallidus (approximately $5 \mathrm{mg}$ wet tissue) was punched out from a section of each rat brain. Tissue was homogenized in $100 \mu \mathrm{l}$ of the sample lysis buffer $(62.5 \mathrm{~mm}$ Tris-HCl pH 6.8, 2\% SDS, 0.5\% NP-40, 5 mm EDTA) plus the protease inhibitor cocktail (Roche Diagnostics Japan, Tokyo, Japan) and heat-denatured. Protein samples were separated by SDS-polyacrylamide gel electrophoresis and transferred to a nitrocellulose membrane. The membrane was probed with antibodies directed against tyrosine hydroxylase (1:1000, Millipore, Bedford, MA, USA), DA transporter (1:1000, Santa Cruz Biotechnology, Santa Cruz, CA, USA), vesicular monoamine transporter 2 (1:1000, Millipore), catechol-O-methyltransferase (1:2000, Millipore) or DA and cyclic AMP-regulated phosphoprotein 32 (DARPP32; 1:500, Santa Cruz Biotechnology). Alternatively, the immunoblots were probed with the antibodies for neuron-specific enolase 
(1:2000, Millipore) and eukaryotic elongation factor 2 (ref. 31) as internal controls. The immunoreactivity of these molecules was visualized by peroxidase-conjugated anti-immunoglobulin antibodies followed by a chemiluminescence reaction (ECL, GE Healthcare, Tokyo, Japan). The intensity of the immunoreactivity, size-matched to the authentic molecular weight, was measured by a CCD camera combined with the image processing software GENETOOLS (Syngene, Cambridge, UK).

Measurement of acoustic startle and prepulse inhibition. Acoustic startle and prepulse inhibition (PPI) responses were measured in a startle chamber (SR-Lab Systems, San Diego Instruments, San Diego, CA, USA) adapted for rats. ${ }^{32}$ The chosen paradigm was used to assess startle amplitude, habituation and PPI response with acoustic stimuli of $120 \mathrm{~dB}$, a single prepulse interval $(100 \mathrm{~ms})$ and three different prepulse intensities $(5,10$ and $15 \mathrm{~dB}$ above background noise (white noise, $70 \mathrm{~dB}$ )). In the PPI test, the five trial types were each repeated eight times in a pseudorandom order to give 40 trials. Each trial type was presented once within a block of five trials.

Measurement of locomotor activity. We measured locomotor activity in a novel environment as described previously. ${ }^{6}$ Each rat was placed in an open field box $(45 \mathrm{~cm}$ length $\times 45 \mathrm{~cm}$ width $\times 30 \mathrm{~cm}$ height, MED Associates, St Albans, VA, USA) under a moderate light level (400 Lx). Line crossings and rearing counts were measured by photo-beam sensors $(25 \mathrm{~mm}$ intervals for horizontal axis and $150 \mathrm{~mm}$ for vertical axis) for $60 \mathrm{~min}$.

Context fear learning and latent inhibition. The test paradigm of contextual conditioning was based on a study by Zhang et al. $^{33}$ In brief, rats were transported to the laboratory at least $30 \mathrm{~min}$ before fear conditioning. Rats were placed in a shock chamber with a stainless steel grid floor $(21.5 \mathrm{~cm}$ width $\times 20.5 \mathrm{~cm}$ depth $\times 30 \mathrm{~cm}$ height box; Ohara Medical Industry, Tokyo, Japan) for 2 min to monitor baseline movement/freezing and then exposed to a tone cue (conditioning stimulus (CS): $60 \mathrm{~dB}, 10 \mathrm{~Hz}, 30 \mathrm{~s}$ ) together with 0.8 $\mathrm{mA}$ electric shocks (unconditioning stimulus: 2-s duration, twice with a 1-min interval). One day after conditioning, rats were returned to the same chamber and exposed to the same CS. The time spent freezing after the CS initiated was recorded by a video camera and averaged every $30 \mathrm{~s}$ with the aid of imaging software (Ohara Medical Industry). Animals in the non-preexposed group were directly subjected to the above conditioning. One day before the conditioning, rats in the preexposed group were placed in the shock chamber for $20 \mathrm{~min}$ and exposed to the same contextual clue (CS) but without receiving electric stimuli (unconditioning stimulus).

In vivo unit recording from nigra dopaminergic neurons. Extracellular single-unit recording was performed at the age of 8-10 weeks under chloral hydrate anesthesia (400 $\mathrm{mg} \mathrm{kg}^{-1}$ i.p.). The recording procedures and analyses were modified from Mameli-Engvall et al. ${ }^{34}$ Anesthetized rats were mounted on a stereotaxic apparatus, and their body temperature was continuously controlled to $37.0 \pm 0.5^{\circ} \mathrm{C}$. The skull overlying the midbrain was removed. A glass microelectrode filled with $0.5 \mathrm{M} \mathrm{NaCl}$ containing $2 \%$ Pontamine Sky Blue (resistance: 15-25 M 2 ) was inserted into the substantia nigra pars compacta. The stereotaxic coordinates were 5.0-5.4 mm posterior and 1.2-1.4 $\mathrm{mm}$ lateral measured from the bregma, $7.5-8.5 \mathrm{~mm}$ below the dura. Neuronal signals were recorded for 3-5 min and amplified using an amplifier (Axoclamp 2B, Molecular Devices, Sunnyvale, CA, USA) connected to a high-gain amplifier (AVH-11, Nihon Kohden, Tokyo, Japan). Single units were constantly monitored by the window discriminator (121 Window Discriminator, World Precision Instruments, Sarasota, FL, USA). The signals were transferred via a digitizer (Digidata 1200, Molecular Devices) to a computer equipped with recording software (Axoscope 1.1, Molecular Devices).

Dopaminergic and non-dopaminergic neurons were distinguished by their characteristic waveform and firing patterns: (1) a typical triphasic action potential with a marked negative deflection; (2) a characteristic long duration (>2.0 ms), an action potential width from start to negative through $>1.1 \mathrm{~ms}$; (3) a slow firing rate $(0.5-10 \mathrm{~Hz})$ with an irregular single spiking pattern and occasional bursting activity. ${ }^{35}$ DA cell firing was analyzed with respect to the average ratio of burst duration and the percentage of spikes within a burst; the number of spikes within bursts divided by total number of spikes as described previously. ${ }^{36}$ Bursts were identified with the following criteria: (1) their onset are defined by two consecutive spikes within an interval lower than $80 \mathrm{~ms}$ and whenever (2) they terminated with an interval greater than 160 ms. $^{36}$

Determination of monoamine contents. Each brain region was homogenized in $0.1 \mathrm{M}$ perchloric acid containing $0.1 \mathrm{~mm}$ EDTA and $100 \mathrm{~nm}$ isoproterenol. After centrifugation, the supernatants and pellets were harvested. Concentrations of DA and its metabolites, 3,4-dihydroxyphenylacetic acid (DOPAC) and homovanillic acid (HVA), in the supernatants were analyzed by high-performance liquid chromatographyelectrochemistry. The mobile phase containing $50 \mathrm{~mm}$ trisodium citrate ( $\mathrm{pH}$ 3.2), $25 \mathrm{~mm} \mathrm{NaH} \mathrm{PO}_{4}, 10 \mathrm{~mm}$ diethylamine, $0.03 \mathrm{~mm}$ EDTA, $2.5 \mathrm{~mm}$ 1-octane sulfonic acid sodium salt, $6 \%$ methanol and $1 \%$ dimethylacetamide was delivered at $0.5 \mathrm{ml} \mathrm{min}^{-1}$. Monoamines were separated on an analytical high-performance liquid chromatography column (CA-50DS, $4.6 \times 150 \mathrm{~mm}^{2}$, Eicom, Kyoto, Japan) and detected with a graphite electrode (WE-3G, Eicom). Data analysis was performed with a data acquisition computer (Powerchrom, Eicom). Tissue pellets were homogenized in $0.5 \mathrm{~N} \mathrm{NaOH}$ and subjected to protein determination with a Micro BCA kit (Pierce). Tissue monoamine contents were normalized with protein concentrations.

Statistical analysis. Results were expressed as mean$\mathrm{s} \pm$ s.e.m. When data were obtained from only two groups, a two-tailed $t$-test or Mann-Whitney's $U$-test was used for comparison. Behavioral scores were initially analyzed using factorial ANOVA with neonatal EGF treatment (two levels), drug challenge or dose (two to four levels), and/or preexposure to CS (two levels) as between-subjects factors and 

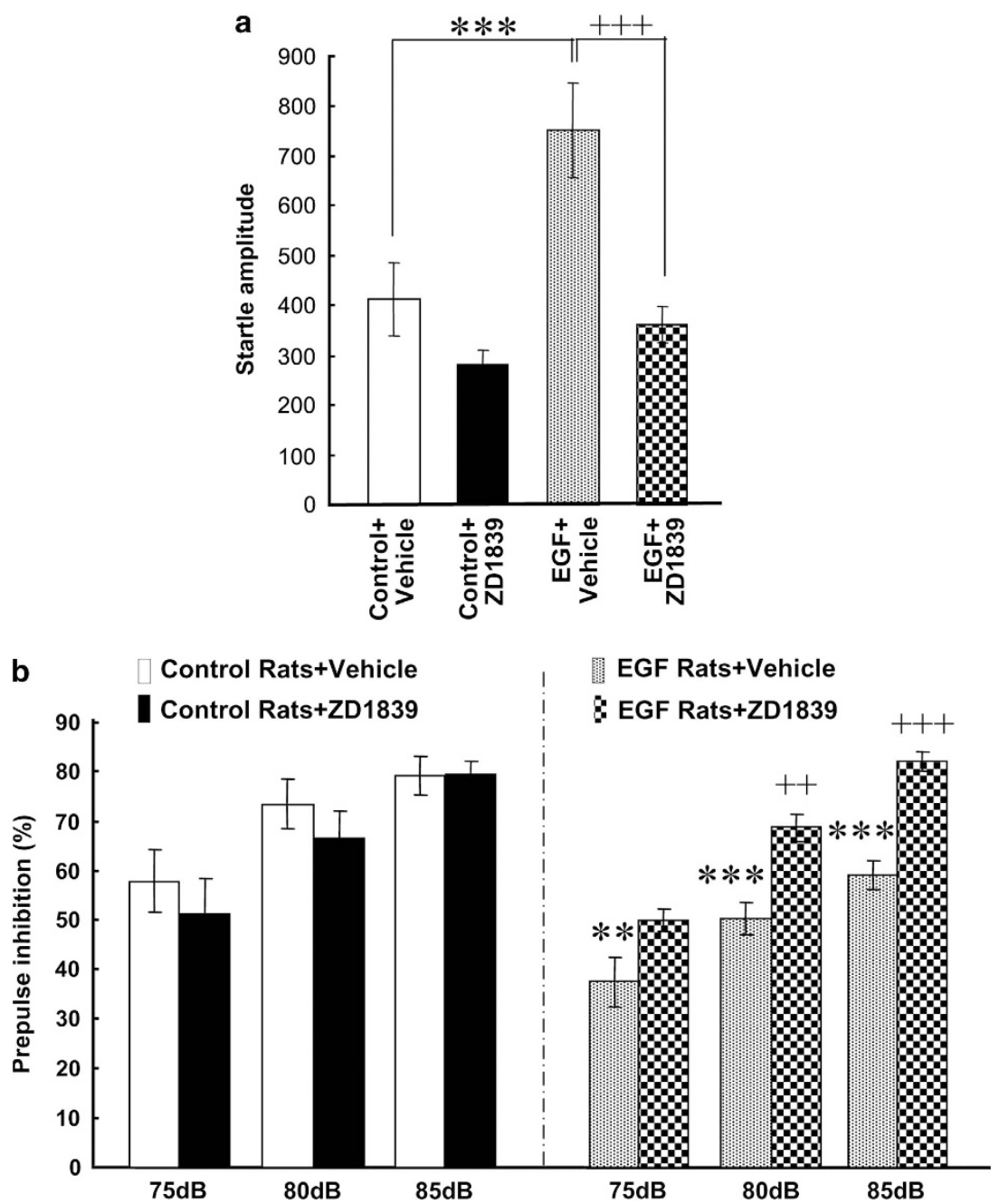

Figure 1 Effects of intraventricular infusion of ZD1839 on pulse-alone startle and prepulse inhibition of epidermal growth factor (EGF) rats. (a) ZD1839 (1 mg ml ${ }^{-1}$; $12 \mu \mathrm{g}$ per day) or vehicle (10\% dimethyl sulfoxide) was administered to the lateral cerebroventricle for 8-10 days. Pulse-alone startle of EGF or control rats with a vehicle or ZD1839 pump was measured with a 120-dB tone as adults. (b) Prepulse inhibition was determined in the presence of 75-, 80- and 85-dB prepulse stimuli. Bars indicate means \pm s.e.m. ( $n=10$ each). ${ }^{* *} P<0.01,{ }^{* * *} P<0.001$, compared with control rats receiving vehicle and ${ }^{++} P<0.01,{ }^{+++} P<0.001$, compared with EGF rats receiving vehicle (by Fisher LSD).

prepulse magnitude (three levels) as a within-subject factor. The interaction of the within-subject factor with betweensubjects factors was estimated by multivariate analysis of variance with Pilli compensation. Subsequently, a Fisher's LSD test was used for a post-hoc test of multiple comparisons. A $P$-value less than 0.05 was regarded as statistically significant. Statistical analyses were performed using SPSS software (SPSS, Yokohama, Japan). The number of animals used in each experiment $(n)$ is listed in parentheses.

\section{Results}

Effects of the ErbB1 inhibitor ZD1839 on acoustic startle and prepulse inhibition. Rats and mice transiently exposed to EGF as neonates exhibit several behavioral deficits relevant to schizophrenia, including startle responses, PPI, latent inhibition and social interaction, and thus were employed for this evaluation study of ErbB inhibitors. , $27,37-39$ We prepared four groups of animals to test one of ErbB inhibitors, ZD1839, in EGF-treated rats (hereafter referred to as EGF rats) and controls. The quinazoline derivative ZD1839 is a newly developed anticancer drug that specifically targets ErbB1. ${ }^{40,41}$ We subchronically administered ZD1839 to the lateral ventricle from an osmotic mini-pump, because this inhibitor has limited permeability through the blood-brain barrier. ${ }^{42}$ Ten days after drug infusion was initiated and when surgical injury and stress subsided, we measured acoustic startle responses and PPI. We found that ZD1839 decreased pulsealone acoustic startle responses in EGF rats (Figure 1a); a two-way repeated ANOVA with the subject factors of EGF and drug (ZD1839) revealed main effects of EGF treatment $\left(F_{1,36}=11.8, P=0.002\right)$ and drug $\left(F_{1,36}=18.4, P<0.001\right)$ and an interaction between EGF and drug $\left(F_{1,36}=4.7\right.$, $P=0.038$ ). Post-hoc tests detected a significant increase of 

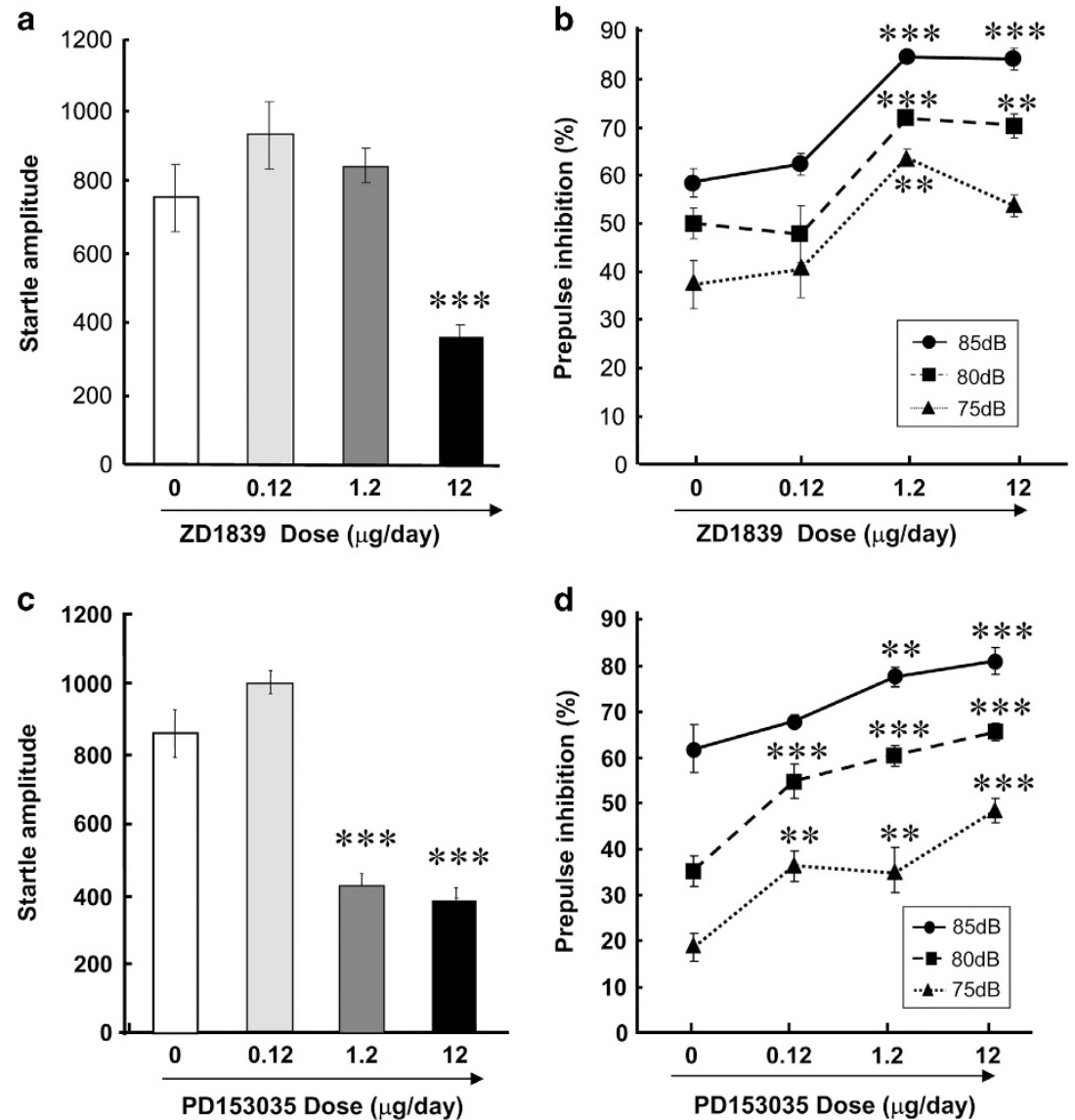

Figure 2 Effects of intraventricular administration of ErbB inhibitors on prepulse inhibition deficits of epidermal growth factor (EGF) rats. ZD1839 (a, b) or PD153035 (c, d) (both $0.12,1.2$ or $12 \mu \mathrm{g}$ per day) or vehicle ( $10 \%$ dimethyl sulfoxide) was administered to the lateral cerebroventricle of EGF rats for 10 days. (a, c) Pulse-alone startle of EGF rats to a 120-dB tone was measured and plotted. (b, d) Prepulse inhibition of the EGF rats receiving doses of ZD1839 or PD153035 was determined in the presence of 7580- and 85-dB prepulse stimuli. Bars indicate means \pm s.e.m. $\left(n=6-10\right.$ each). ${ }^{\star \star} P<0.01,{ }^{\star \star *} P<0.001$, compared with EGF rats receiving vehicle by Fisher LSD.

Table 1 Inhibition of ErbB1 phosphorylation in vivo

\begin{tabular}{lcc}
\hline Brain region & Vehicle & $P D 153035$ \\
\hline Prefrontal cortex & $0.196 \pm 0.017$ & $0.174 \pm 0.034$ \\
Basal ganglia & $0.292 \pm 0.025$ & $0.198 \pm 0.019^{\star *}$ \\
Hippocampus & $0.226 \pm 0.009$ & $0.142 \pm 0.017^{*}$ \\
Hypothalamus & $0.330 \pm 0.039$ & $0.296 \pm 0.016$ \\
Midbrain & $0.274 \pm 0.011$ & $0.282 \pm 0.031$
\end{tabular}

Brain tissue lysates were prepared from the prefrontal cortex, basal ganglia (that is, striatum + nucleus accumbens + globus pallidus), hippocampus, hypothalamus and midbrain of epidermal growth factor (EGF) rats receiving vehicle ( $10 \%$ dimethyl sulfoxide) or PD153035 (12 $\mu \mathrm{g}$ per day) for 12 days $(n=5$ rats each). Lysates were subjected to an enzyme immunoassay for phosphoErbB1 with the cell lysate from an EGF-stimulated A431 cells as a standard. Data are expressed as mean \pm s.e.m. (arbitrary units). ${ }^{*} P<0.05$, ${ }^{\star \star} P<0.01$ by Fisher's LSD.

pulse-alone startle responses of EGF rats receiving vehicle (that is, $10 \%$ DMSO) compared with control rats receiving vehicle. The increase of pulse-alone startle responses of EGF rats was attenuated by ZD1839 infusion.

For PPI levels, a three-way repeated ANOVA with the between-subjects factors of EGF and drug (ZD1839) and the within-subject factor of prepulse revealed a main effect of EGF treatment $\left(\mathrm{F}_{1,36}=8.53, \quad P=0.006\right)$ and an interaction between EGF and drug $\left(F_{1,36}=10.6, P=0.003\right)$ (Figure 1b). There was no significant interaction between EGF and prepulse, however $\left(\mathrm{F}_{6,72}=0.840, P=0.543\right)$. Post-hoc analyses detected a significant effect of ZD1839 in the EGF group, but not in the control group. Thus, ZD1839 infusion ameliorated the PPI deficits of EGF rats.

To validate a potential mathematical interaction between startle response and $\mathrm{PPI}$, we determined the dose-responsiveness of PPI to ZD1839 in EGF rats. The four doses of ZD1839 (that is, $0,0.12,1.2$ and $12 \mu \mathrm{g}$ per day) were given subchronically to EGF rats (Figures $2 a$ and $b$ ). We found that ZD1839 decreased the amplitude of pulse-alone startle response in a dose-dependent manner $\left(F_{1,18}=28.9\right.$, $P=0.002$; Figure 2a). Post-hoc analyses revealed that only the highest dose $(12 \mu \mathrm{g}$ per day) resulted in a decrease in startle response $(P<0.003)$. Reciprocally, the PPI levels of EGF rats were elevated by increasing doses of ZD1839 $\left(\mathrm{F}_{3,28}=10.4, P<0.001\right.$; Figure $\left.2 \mathrm{~b}\right)$.

We similarly tested the behavioral effects of another ErbB inhibitor, PD153035 (Figures 2c and d). This inhibitor has a broader spectrum for ErbB1-4 receptors. ${ }^{27}$ Startle responses of EGF rats were significantly attenuated by increasing PD153035 doses $\left(F_{1,36}=49.3, P<0.001\right.$; Figure $\left.2 c\right)$. Posthoc analyses suggest that the startle responses of EGF rats 

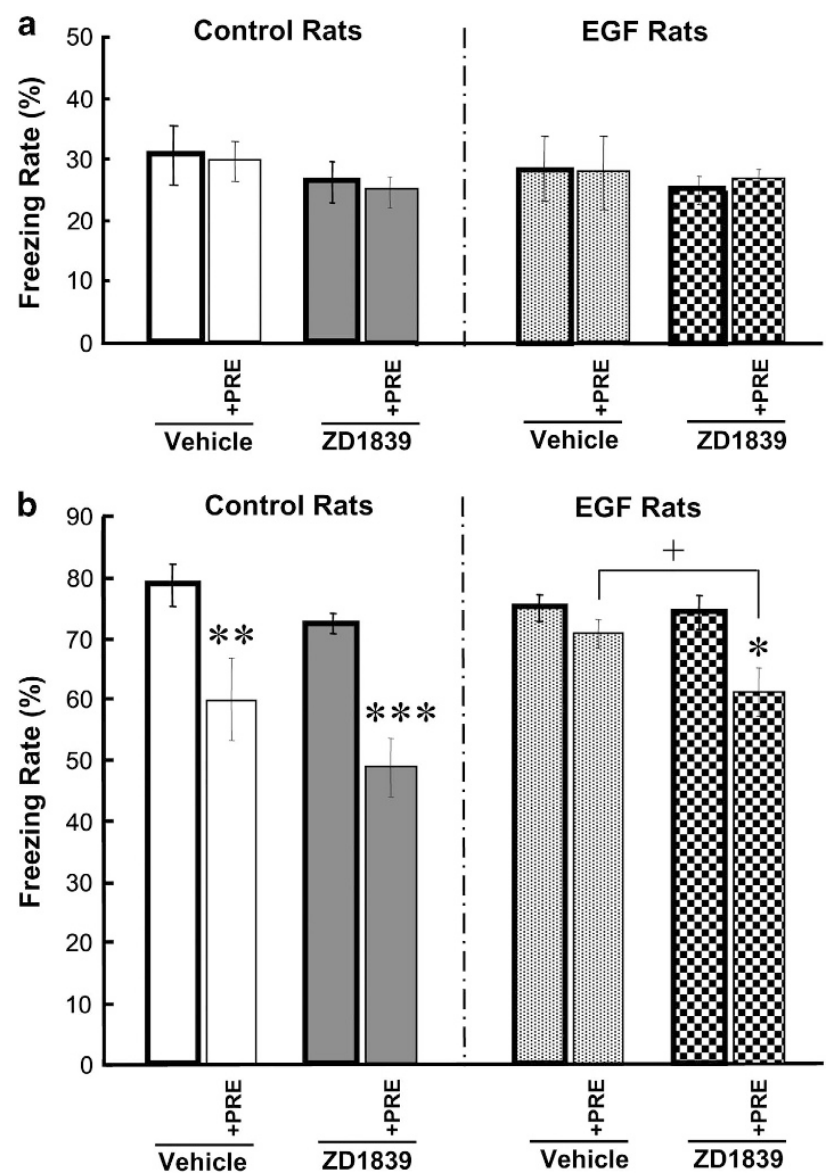

Figure 3 ZD1839 effects on latent inhibition of tone-dependent fearconditioning. ZD1839 $\left(1 \mathrm{mg} \mathrm{ml}^{-1} ; 12 \mu \mathrm{g}\right.$ per day) or vehicle (10\% dimethyl sulfoxide) was administered to the lateral cerebroventricle of rats treated with epidermal growth factor (EGF) or a control protein as neonates. Learning ability and latent inhibition in EGF and control rats were determined with a tone-paired fearconditioning procedure and compared between vehicle- and ZD1839-infused groups. One day before the conditioning, rats in the preexposure group had been preexposed to the same tone cue without shock ( + PRE; $n=10$ each). Rats in the non-preexposure group were directly subjected to conditioning on day 8 ( $n=10$ each). Mean freezing rates (\%) were measured for 2 min during conditioning (a) or during tone exposure in the test paradigm (b) Data represent means \pm s.e.m. ${ }^{\star} P<0.05, \quad{ }^{* *} P<0.01, \quad{ }^{* * *} P<0.001$, compared between preexposed and non-preexposed groups and ${ }^{+} P<0.05$, compared between vehicle- and drugtreated groups (by Fisher LSD).

were significantly decreased at the higher doses (1.2 and $12 \mu \mathrm{g}$ per day). A two-way repeated ANOVA revealed that the dose of PD153035 exhibited a significant main effect on PPI levels $\left(F_{3,18}=30.2, \quad P<0.001\right)$, but no interaction with prepulse $\left(F_{6,72}=1.72, P=0.128\right.$; Figure $\left.2 \mathrm{~d}\right)$. Post-hoc tests detected that PD153035 (0.12-12 $\mu \mathrm{g}$ per day) significantly ameliorated the PPI deficits of EGF rats. Of note, the lowest dose of PD153035 ( $0.12 \mu \mathrm{g}$ per day) and the middle dose of ZD1839 (1.2 $\mu \mathrm{g}$ per day) both ameliorated the PPI deficits of EGF rats without altering their startle amplitudes, suggesting the independency of PPI levels from the magnitude of pulsealone startle responses in these experiments.

The ErbB1 inhibition of ZD1839 in vivo, but not that of PD153035, had been verified in our previous study. ${ }^{25}$ To control that of PD153035, here, we measured ErbB1 a

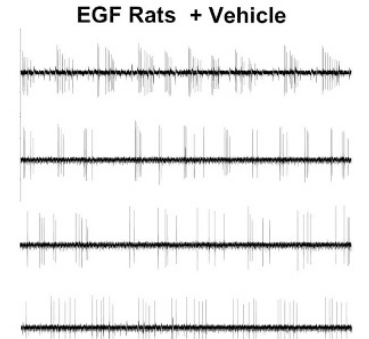

b
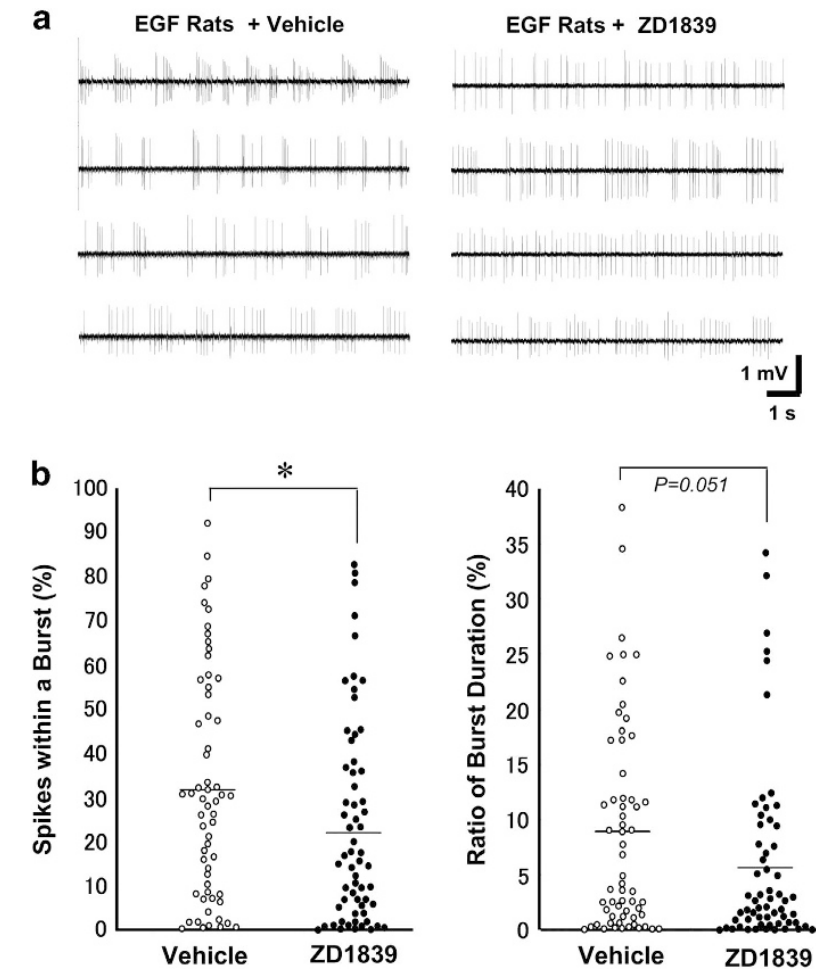

Figure 4 Effects of ZD1839 on firing activities of nigral dopamine neurons in epidermal growth factor (EGF) rats. ZD1839 $\left(0.2 \mathrm{mg} \mathrm{ml}^{-1} ; 2.4 \mu \mathrm{g}\right.$ per day) or vehicle ( $10 \%$ dimethyl sulfoxide) was administered to the lateral cerebroventricle of EGF rats for 10-13 days. In vivo extracellular recording was performed in the substantia nigra pars compacta ( $n=61-63$ cells from five rats each). Spontaneous unit activity of dopamine neurons was identified with the criteria of spike features and patterns (see Material and methods). ${ }^{34-36}$ (a) Typical traces of single-unit activity were shown for display. (b) The percentage of the number of spikes within a burst and a ratio of burst duration were calculated for individual cells and compared between groups by Mann-Whitney's $U$-test; ${ }^{*} P<0.05$. Horizontal lines represent mean values of the distributions.

phosphorylation levels in various brain tissues of EGF rats receiving vehicle (10\% DMSO) or PD153035 (12 $\mu$ g per day; Table 1). A two-way ANOVA revealed significant main effects of PD153035 $\left(F_{1,40}=8.94, P=0.005\right)$ and brain region $\left(F_{1,40}=11.3, P<0.001\right)$ but no interaction between EGF and brain region $\left(F_{1,40}=1.61, P=0.190\right)$; this confirms the inhibitory action of PD153035 on ErbB1 phosphorylation. Post-hoc analyses detected significant differences of ErbB1 phosphorylation in the basal ganglia and hippocampus between groups, confirming the authenticity of PD153035 action in vivo.

Amelioration of latent inhibition scores with ZD1839. We also evaluated an effect of the ErbB1 inhibitor ZD1839 on fear learning and latent inhibition. EGF and control rats were subjected to fear conditioning in the presence or absence of preexposure to the tone cue (CS; Figure 3). An initial threeway ANOVA for freezing levels during conditioning with the subjects factors of EGF $(+/-)$, drug $(+/-)$ and preexposure to CS $(+/-)$ detected no main effects of these factors $\left(F_{1,72}=0.016-2.62, P=0.110-0.900\right)$ and no interactions $\left(F_{1,72}=0.016-0.180, P=0.673-0.900\right) \quad$ (Figure 3a). This suggests that neither EGF nor drug administration nor 

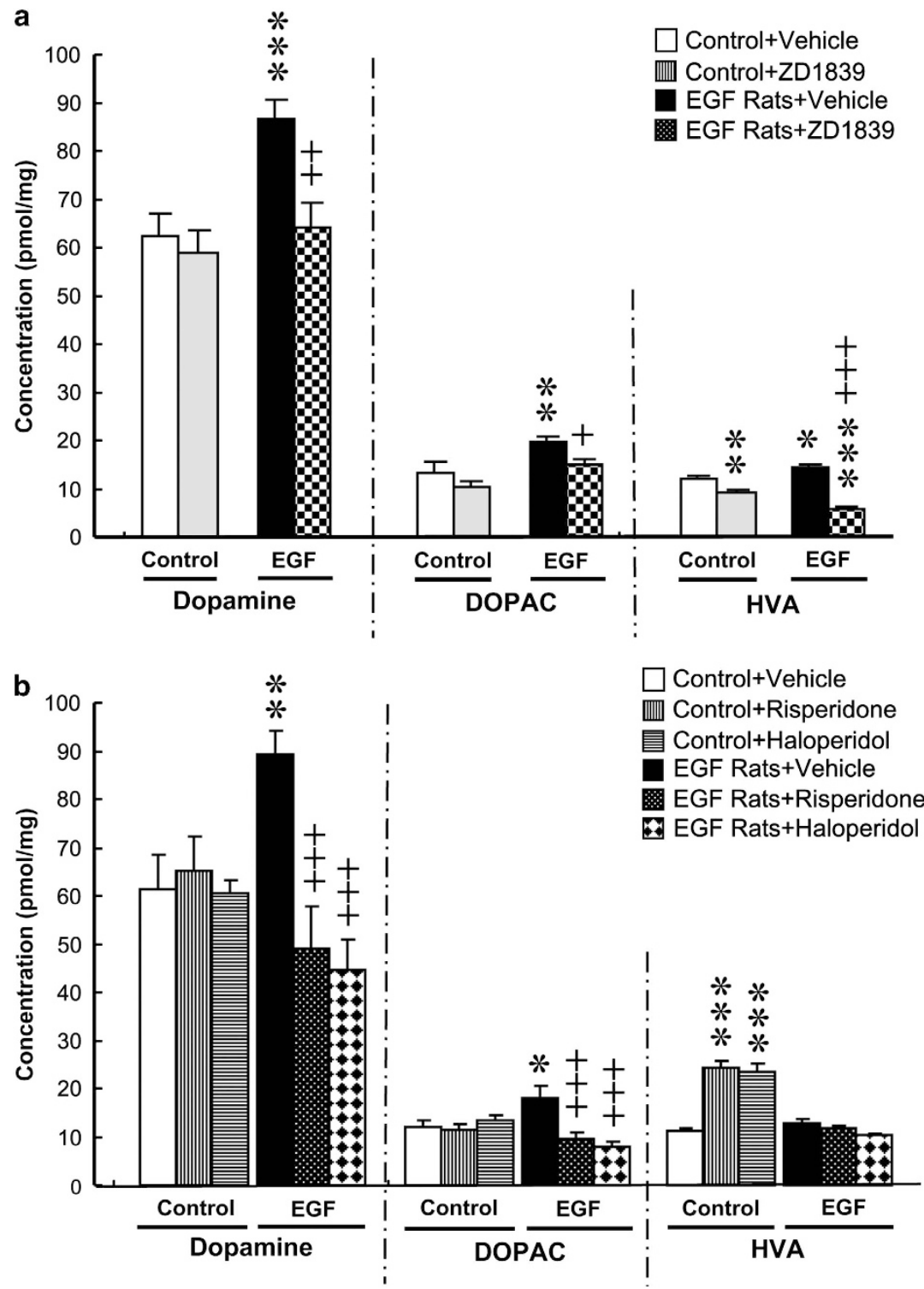

Figure 5 Effects of ZD1839 and conventional antipsychotics on pallidal dopamine metabolism. (a) ZD1839 (12 $\mu$ g per day, intraventricular), (b) risperidone (1.0 mg per day) or haloperidol ( $0.3 \mathrm{mg}$ per day) was subchronically administered to epidermal growth factor (EGF) and control rats for 10-13 days. Monoamines were then extracted from the globus pallidus, and tissue concentrations of dopamine, 3,4-dihydroxyphenylacetic acid (DOPAC) and homovanillic acid (HVA) were measured by high-performance liquid chromatography combined with an electrochemical detector. ${ }^{\star} P<0.05,{ }^{* \star} P<0.01,{ }^{* \star *} P<0.001$, compared with control rats receiving vehicle and ${ }^{+} P<0.05,{ }^{++} P<0.01$, $+++P<0.001$, compared with EGF rats receiving vehicle by Fisher LSD.

preexposure to CS altered shock sensitivity. In contrast, a three-way ANOVA for learning scores during the test period revealed main effects of EGF $\left(F_{1,72}=5.92, P=0.018\right)$, preexposure $\left(\mathrm{F}_{1,72}=34.0, P<0.001\right)$ and drug $\left(\mathrm{F}_{1,72}=8.92\right.$, $P=0.004)$ including a significant interaction between EGF and preexposure $\left(\mathrm{F}_{1,72}=5.92, P=0.018\right)$. Post-hoc comparisons revealed that control rats exhibited preexposure-driven decreases in learning scores in both vehicle- and drugtreated groups, whereas EGF rats showed a decrease only in the drug-treated group (Figure $3 b$ ). These results suggest that the latent inhibition of fear learning was disrupted in EGF rats but the deficit was ameliorated by ZD1839 treatment.

ZD1839 effects on the firing activity of nigral DA neurons in vivo. Our previous studies indicate that pallidal DA release and potentially the neural activity of DA neurons are upregulated in EGF rats. ${ }^{43}$ To assess the direct impact of ZD1839 administration on nigral DA neurons in EGF rats, we performed single-unit recording from these neurons in an anesthetic condition (Figure 4). ZD1839 infusion altered the firing pattern of dopaminergic neurons, although there was no significant difference in mean firing rates; $4.43 \pm 0.22 \mathrm{~Hz}$ in EGF rats receiving vehicle and $4.05 \pm 0.22 \mathrm{~Hz}$ in EGF rats receiving ZD1839. ZD1839 infusion resulted in a significant decrease in the index of spikes within a burst; $32.4 \pm 3.3 \%$ for EGF rats receiving vehicle and $23.7 \pm 3.2 \%$ for EGF rats receiving $Z D 1839(U=1505, P=0.037)$. Mean percentage of burst duration also exhibited marginal significance toward the reduction $(U=1531, P=0.051)$. The burst firing of DA neurons is known to drive phasic DA release from their 


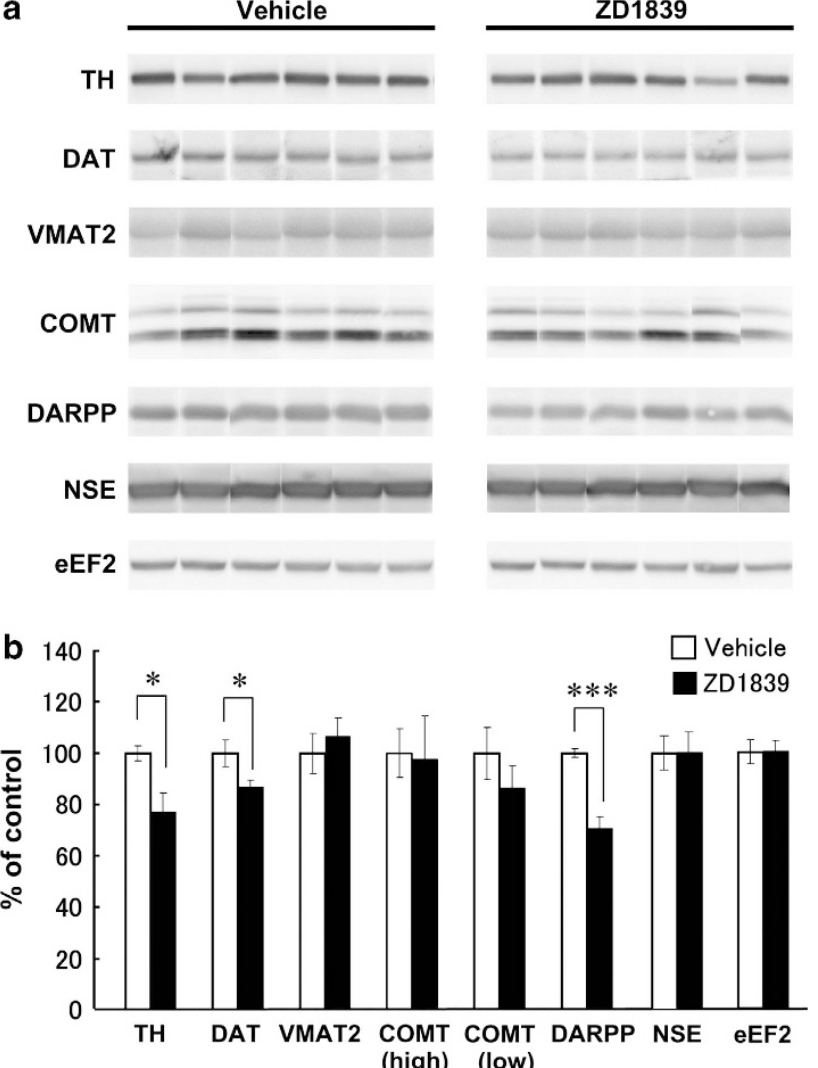

Figure 6 Effects of ZD1839 on dopaminergic markers in the globus pallidus of epidermal growth factor (EGF) rats. (a) A protein extract was prepared from the globus pallidus of EGF rats receiving ZD1839 or vehicle (8-week old, $n=6$ rats each) and subjected to SDS-polyacrylamide gel electrophoresis. Immunoblots were probed with the antibodies directed against tyrosine hydroxylase $(\mathrm{TH})$, vesicular monoamine transporter 2 (VMAT2), dopamine transporter (DAT), DARPP32 and catechol-0-methyltransferase (COMT) as well as with those against neuron-specific enolase (NSE) and eukaryotic elongation factor 2 (eEF2; internal controls). Immunoreactivity on a blot was captured by a cooled CCD camera and measured by imaging software. (b) The percentage ratio normalized to control rats was calculated and plotted (mean \pm s.e.m.). ${ }^{*} P<0.05,{ }^{* * *} P<0.001$ by two-tailed $t$-test.

terminals. $^{34-36}$ Therefore, these results indicate that ErbB1 inhibition in the brain attenuates the bursting activity of nigral DA neurons in EGF rats, leading to the anti-dopaminergic influences on this model.

ZD1839 and antipsychotic drugs normalize pallidal dopaminergic metabolism. The above electrophysiological results suggest that the ErbB1 inhibitor acts on midbrain dopaminergic neurons. To assess the pharmacological consequence of ZD1839 infusion for dopaminergic states in their target regions, we measured the tissue content of DA and its metabolites (DOPAC and HVA) in the frontal cortex, striatum, nucleus accumbens, globus pallidus and hippocampus. Except the globus pallidus, all the other regions of vehicle-infused EGF rats exhibited the complex patterns of increases in DA, DOPAC and/or HVA levels, compared with those in vehicle-infused control rats (Supplementary Table 1). Among those brain regions, ZD1839 infusion to EGF rats ameliorated the pallidal abnormalities in all DA, HVA and DOPAC levels (Figure 5a). The anti-dopaminergic effects were most remarkable in this brain region. The regional effects are in consistent with the fact that the pallidal hyperdopaminergic state underlies the PPI deficits of EGF rats. ${ }^{43}$ In the other brain regions, however, the drug administration failed to exhibit such consistency among metabolites or between EGF and control rats.

Similar pharmacological effects on pallidal DA metabolism were observed following subchronic administration of conventional antipsychotics, haloperidol and risperidone to EGF rats (Figure $5 \mathrm{~b}$ ). These antipsychotics normalized DA content and DOPAC levels in the globus pallidus of EGF rats. These results suggest that the ErbB1 inhibitor mimics conventional antipsychotics to ameliorate the pallidal hyperdopaminergic state of this model.

Effects of ZD1839 on pallidal dopaminergic phenotypes of EGF rats. In our previous paper, we show that the protein levels of dopaminergic markers (that is, tyrosine hydroxylase, VMAT and DA transporter) are upregulated in the globus pallidus of EGF rats. ${ }^{43}$ In the present study, we examined whether the ErbB1 inhibitor can produce the opposite effects on these markers as well as the molecules that contribute to DA metabolism and signaling, catechol-O-methyltransferase and DARPP32 (Figure 6). For internal controls, we used neuron-specific enolase and eukaryotic elongation factor 2 to estimate the density of neurons and cells in the tissue samples, respectively. We found significant decreases in tyrosine hydroxylase and DA transporter levels in EGF rats receiving ZD1839 compared with those receiving vehicle. In addition, the ErbB1 inhibitor markedly diminished DARPP32 immunoreactivity in EGF rats. In contrast, the inhibitor did not change the immunoreactivities of catechol$O$-methyltransferase and VMAT2 or those of neuron-specific enolase and eukaryotic elongation factor 2, although there is a basal increase in VMAT levels in EGF rats. ${ }^{43}$ These results suggest that intracerebroventricular administration of ZD1839 diminished the expression of the molecules involved in DA synthesis and uptake. However, the individual molecules affected by the ErbB1 inhibitor were not identical to those that are implicated in pallidal neuropathology of this model. ${ }^{43}$

Limited physical influences of intraventricular administration of ZD1839. We assessed potential aversive effects of ZD1839 by monitoring body weight gain and measuring locomotor activity. Subchronic intraventricular infusion of ZD1839 did not alter locomotion as monitored by an exploratory behavior test (Supplementary Table 2). A twoway ANOVA for traveled distance revealed no significant effects of EGF $\left(\mathrm{F}_{1,23}=3.60, \quad P=0.071\right)$ or ZD1839 $\left(F_{1,23}=0.327, P=0.573\right)$ and no interactions $\left(F_{1,23}=0.035\right.$ $P=0.852)$. Similarly, the mean weight gain during the 14-day medication period was not significantly influenced by either EGF $\left(F_{1,23}=0.184, P=0.672\right)$ or ZD1839 $\left(F_{1,23}=1.10\right.$, $P=0.306)$, and there was no interaction $\left(\mathrm{F}_{1,23}=1.31\right.$, $P=0.265$; Supplementary Table 2$)$. These results indicate that aversive effects of ZD1839 infusion appear to be limited at the given dose and with the present procedure. 


\section{Discussion}

The stimulation of brain ErbB1 elevates DA release and produces DA-related behavioral deficits in adulthood. ${ }^{6,8}$ Thus, we hypothesized that the attenuation of ErbB1 signaling exerts anti-dopaminergic pharmacology and ameliorates DArelated behavioral impairments. ${ }^{10,39}$ To test this hypothesis, we performed intraventricular infusion of the specific ErbB1 inhibitor (ZD1839) and the broad ErbB1-4 inhibitor (PD153035) in an animal model for schizophrenia and examined their effects on dopaminergic neurons and metabolism as well as on DA-associated behaviors.

Using the cytokine-induced animal model for schizophrenia, we obtained the following results from the present experiments. (1) Subchronic intraventricular infusion of ZD1839 and PD153035 ameliorated the PPI deficits in a dose-dependent manner. (2) These ErbB inhibitors normalized pulse-alone startle increases of this animal model, although the effective doses of the inhibitors significantly differed between pulse-alone startle and PPI. (3) ZD1839 also ameliorated the disruption of latent inhibition of learning in the tone-paired fear conditioning paradigm. (4) The ZD1839 infusion significantly reduced burst firing rates of nigral DA neurons. (5) ZD1839 also diminished several dopaminergic markers and DA metabolism in the globus pallidus of EGF rats. It is reported that the behavioral deficits in sensorimotor gating and latent inhibition of learning involve abnormal DA neurotransmission and may represent the behavioral endophenotypes relevant to positive symptoms of schizophrenia. $^{44,45}$ In the present study, however, PD153035 failed to ameliorate the social interaction deficit of this model (Supplementary Figure 1). Thus, ErbB1 inhibitors appear to be effective on the behavioral endophenotypes relevant to the positive symptoms.

The present animal model was established by transient exposure to EGF and evoked abnormal ErbB signaling during the neonatal stage. ${ }^{1,6}$ Thus, we assume no direct interaction of EGF exposure and ErbB inhibitor challenge in adulthood with the given 6-week interval. Although hyper ErbB1 signals might persist until adulthood in any part(s) of the brain, our preliminary studies fail to obtain an evidence for this assumption (data not shown). We employed the EGF model in this pharmacological study, whose neuropathology and behavioral deficits we have relatively well characterized. ${ }^{43,46-}$ 48 In contrast, the neuropathological underpinnings and/or affected brain region(s) are often not fully characterized in other animal models. ${ }^{48-50}$ Indeed, we previously tested ErbB inhibitors in the other models using neonatal hippocampal lesion and methamphetamine challenge to assess their antipsychotic-like actions. ${ }^{24,25}$ Therefore, the given effectiveness of ErbB1 inhibitors in multiple animal models suggests that ErbB inhibitors might exert universal anti-dopaminergic effects on behavioral endophenotypes relevant to schizophrenia, irrespective of the etiologic origins of individual animal models.

Nigral DA neurons express ErbB1 and ErbB4 receptors and their mRNAs. ${ }^{4,5}$ Furthermore, local challenge with EGF evokes DA release and metabolism in several brain regions. ${ }^{8}$ Corroborating these reports, the present study demonstrated that the blockade of endogenous ErbB1 signaling with
ZD1839 decreased the bursting activity of nigral DA neurons and attenuated pallidal DA metabolism. However, the results from the single-unit recording showed significant overlaps in the distributions of the bursting indices of individual cells between ZD1839-infused and vehicle-infused groups. The overlaps suggest that a certain subpopulation, but not all, of the nigral DA neurons presumably responded to this inhibitor. Although the intraventricular administration of the ErbB1 inhibitor caused the attenuation of ErbB1 phosphorylation in various brain regions, we initially assumed that the globus pallidus would be the target site of ErbB1-kinase inhibition and tested this hypothesis. However, it was not the case; the direct intrapallidal infusion of ZD1839 failed to mimic the action of its intraventricular administration (Supplementary Figure 2). Subchronic intrapallidal infusion of ZD1839 had no significant effects on PPI levels of EGF rats. This discrepancy indicates that the region(s) where ZD1839 bound and reacted is presumably different from the area responsible for the behavioral deficits and neuropathology of this model (that is, globus pallidus). ${ }^{43,51}$ In this context, several questions regarding the pharmacological mechanism of ErbB1-kinase inhibitors still remain.

Subchronic treatment with clozapine or risperidone ameliorates the behavioral deficits of PPI and latent inhibition of the current EGF model. ${ }^{6,43}$ Interestingly, the quinazoline ErbB1 inhibitor and conventional antipsychotics exhibit a similar pharmacological profile in pallidal DA metabolism. We found that ZD1839 and risperidone both normalized the high DA content and attenuated local DA metabolism in the globus pallidus of EGF rats. This anti-dopaminergic phenomenon of risperidone is in accordance with our previous report that this antipsychotic normalizes the increased DA release in the globus pallidus of EGF rats as measured by microdialysis. ${ }^{38}$ However, the chemical nature of affected DA metabolites differed between ZD1839 and risperidone; the ErbB1 inhibitor markedly decreased both DOPAC and HVA contents, whereas risperidone decreased only DOPAC content. In addition, there are some activity differences between these drugs; risperidone has moderate effects on the higher pulsealone startle amplitudes of EGF rats, whereas the ErbB inhibitors markedly decreased startle amplitudes. ${ }^{43}$ In addition, risperidone, but not PD153035, ameliorated the deficits in social interaction of EGF rats (MM, unpublished data). Therefore, the pharmacological actions of quinazoline ErbB1 inhibitors are similar but not identical to the conventional antipsychotics.

There is a potential pharmacological link between the ErbB signal and conventional antipsychotics. ${ }^{52,53}$ In the fontal cortex of normal rats, chronic treatment of rats with haloperidol and clozapine decreased ErbB4 levels and neuregulin-1, respectively. ${ }^{54,55}$ Pereira et al. ${ }^{19,56}$ reported the recruitment of ErbB1 signaling with clozapine; that is, a single shot of clozapine triggers positive ErbB1 signaling in the frontal cortex of rats, which the authors implicated in the unique antipsychotic profile of this drug. The different doses and design of antipsychotic administration often result in the opposing molecular signals or distinct pharmacological consequences. ${ }^{57}$ Thus, these previous reports might not contradict the present results and both support the involvement of ErbB signaling in antipsychotic pharmacology. We hope that ErbB 
inhibitors could be developed as a novel prodrug for the schizophrenia symptoms involving dopaminergic dysfunction.

\section{Conflict of interest}

\author{
Higeta Shoyu Co., Ltd., provided recombinant EGF for this \\ study.
}

Acknowledgements. We are grateful for Higeta Shoyu Co., Ltd. for providing recombinant EGF for this study. This work was supported by MEXT KAKENHI (No. 24116010), JSPS KAKENHI (No. 22300107, No. 22790245, №. 20790203, No. 24590314 and No. 23500464) and a grant for Promotion of Niigata University Research Projects.

1. Futamura T, Toyooka K, Iritani S, Niizato K, Nakamura R, Tsuchiya K et al. Abnormal expression of epidermal growth factor and its receptor in the forebrain and serum of schizophrenic patients. Mol Psychiatry 2002; 7: 673-682.

2. Stefansson H, Sigurdsson E, Steinthorsdottir V, Bjornsdottir S, Sigmundsson T, Ghosh S et al. Neuregulin 1 and susceptibility to schizophrenia. Am J Hum Genet 2002; 71: 877-892.

3. Seroogy KB, Numan S, Gall CM, Lee DC, Kornblum HI. Expression of EGF receptor mRNA in rat nigrostriatal system. Neuroreport 1994; 6: 105-108.

4. Steiner H, Blum M, Kitai ST, Fedi P. Differential expression of ErbB3 and ErbB4 neuregulin receptors in dopamine neurons and forebrain areas of the adult rat. Exp Neurol 1999; 159: 494-503.

5. Abe $\mathrm{Y}, \mathrm{Namba} \mathrm{H}, \mathrm{Zheng} \mathrm{Y}, \mathrm{Nawa} \mathrm{H}$. In situ hybridization reveals developmental regulation of ErbB1-4 mRNA expression in mouse midbrain: implication of ErbB receptors for dopaminergic neurons. Neuroscience 2009; 161: 95-110.

6. Futamura T, Kakita A, Tohmi M, Sotoyama H, Takahashi H, Nawa H. Neonatal perturbation of neurotrophic signaling results in abnormal sensorimotor gating and social interaction in adults: implication for epidermal growth factor in cognitive development. $\mathrm{Mol}$ Psychiatry 2003; 8: 19-29.

7. Yurek DM, Zhang L, Fletcher-Turner A, Seroogy KB. Supranigral injection of neuregulin1beta induces striatal dopamine overflow. Brain Res 2004; 1028: 116-119.

8. Mizuno $M$, Sotoyama $H$, Narita $E$, Kawamura $H$, Namba $H$, Zheng $Y$ et al. A cyclooxygenase-2 inhibitor ameliorates behavioral impairments induced by striatal administration of epidermal growth factor. J Neurosci 2007; 27: 10116-10127.

9. Zhang L, Fletcher-Turner A, Marchionni MA, Apparsundaram S, Lundgren KH, Yurek DM et al. Neurotrophic and neuroprotective effects of the neuregulin glial growth factor-2 on dopaminergic neurons in rat primary midbrain cultures. J Neurochem 2004; 91 : 1358-1368.

10. Iwakura Y, Zheng Y, Sibilia M, Abe Y, Piao YS, Yokomaku D et al. Qualitative and quantitative re-evaluation of epidermal growth factor-ErbB1 action on developing midbrain dopaminergic neurons in vivo and in vitro: target-derived neurotrophic signaling (Part 1): J Neurochem 2011; 118: 45-56.

11. Carlsson $T$, Schindler FR, Höllerhage M, Depboylu C, Arias-Carrión O, Schnurrbusch $S$ et al. Systemic administration of neuregulin- $1 \beta 1$ protects dopaminergic neurons in a mouse model of Parkinson's disease. J Neurochem 2011; 117: 1066-1074.

12. Kwon OB, Paredes D, Gonzalez CM, Neddens J, Hernandez L, Vullhorst D et al. Neuregulin-1 regulates LTP at CA1 hippocampal synapses through activation of dopamine D4 receptors. Proc Natl Acad Sci USA 2008; 105: 15587-15592.

13. Tomiyama K, O'Tuathaigh CM, O'Sullivan GJ, Kinsella A, Lai D, Harvey RP et al. Phenotype of spontaneous orofacial dyskinesia in neuregulin-1 'knockout' mice. Prog Neuropsychopharmacol Biol Psychiatry 2009; 33: 330-333.

14. Kato T, Kasai A, Mizuno M, Fengyi L, Shintani N, Maeda S et al. Phenotypic characterization of transgenic mice overexpressing neuregulin-1. PLOS ONE 2010; 5: e14185.

15. Kato T, Abe Y, Sotoyama H, Kakita A, Kominami R, Hirokawa S et al. Transient exposure of neonatal mice to neuregulin-1 results in hyperdopaminergic states in adulthood: implication in neurodevelopmental hypothesis for schizophrenia. Mol Psy 2011; 16: 307-320.

16. Harrison PJ, Law AJ. Neuregulin 1 and schizophrenia: genetics, gene expression, and neurobiology. Biol Psychiatry 2006; 60: 132-140.

17. Mei L, Xiong WC. Neuregulin 1 in neural development, synaptic plasticity and schizophrenia. Nat Rev Neurosci 2008; 9: 437-452.

18. Nawa $\mathrm{H}$, Takei $\mathrm{N}$. Recent progress in animal modeling of immune inflammatory processes in schizophrenia: implication of specific cytokines. Neurosci Res 2006; 56: 2-13.

19. Pereira A, Sugiharto-Winarno A, Zhang B, Malcolm P, Fink G, Sundram S. Clozapine induction of ERK $1 / 2$ cell signalling via the EGF receptor in mouse prefrontal cortex and striatum is distinct from other antipsychotic drugs. Int J Neuropsychopharmacol 2012; 15: $1149-1160$.
20. Iwakura Y, Wang R, Abe Y, Piao YS, Shishido Y, Higashiyama S et al. Dopaminedependent ectodomain shedding and release of epidermal growth factor in developing striatum: target-derived neurotrophic signaling (Part 2): J Neurochem 2011; 18: 57-68.

21. Iwakura Y, Piao YS, Mizuno M, Takei N, Kakita A, Takahashi H et al. Influences of dopaminergic lesion on epidermal growth factor-ErbB signals in Parkinson's disease and its model: neurotrophic implication in nigrostriatal neurons. J Neurochem 2005; 93: 974-983.

22. Silberberg G, Darvasi A, Pinkas-Kramarski R, Navon R. The involvement of ErbB4 with schizophrenia: association and expression studies. Am J Med Genet B Neuropsychiatr Genet 2006; 141B: 142-148.

23. Iwakura $Y$, Nawa H. ErbB1-4-dependent EGF/neuregulin signals and their cross talk in the central nervous system: pathological implications in schizophrenia and Parkinson's disease. Front Cell Neurosci 2013; 7: 4.

24. Mizuno M, Iwakura Y, Shibuya M, Zheng Y, Eda T, Kato T et al. Antipsychotic potential of quinazoline ErbB1 inhibitors in a schizophrenia model established with neonatal hippocampal lesioning. J Pharmacol Sci 2010; 114: 320-331.

25. Nawa $\mathrm{H}$, Mizuno M. Antipsychotic molecular-targeting epithelial growth factor receptor. United States Patent Application 20060167026.

26. Wang C, McInnis J, Ross-Sanchez M, Shinnick-Gallagher P, Wiley JL, Johnson KM. Longterm behavioral and neurodegenerative effects of perinatal phencyclidine administration: implications for schizophrenia. Neuroscience 2001; 107: 535-550.

27. Tohmi M, Tsuda N, Mizuno M, Takei N, Frankland PW, Nawa H. Distinct influences of neonatal epidermal growth factor challenge on adult neurobehavioral traits in four mouse strains. Behav Genet 2005; 35: 615-629.

28. Bridges AJ, Zhou H, Cody DR, Rewcastle GW, McMichael A, Showalter HD et al. Tyrosine kinase inhibitors. 8. An unusually steep structure-activity relationship for analogues of 4-(3bromoanilino)-6,7-dimethoxyquinazoline (PD 153035), a potent inhibitor of the epidermal growth factor receptor. J Med Chem 1996; 39: 267-276.

29. Moulder SL, Yakes FM, Muthuswamy SK, Bianco R, Simpson JF, Arteaga CL. Epidermal growth factor receptor (HER1) tyrosine kinase inhibitor ZD1839 (Iressa) inhibits HER2/neu (erbB2)-overexpressing breast cancer cells in vitro and in vivo. Cancer Res 2001; 61: 8887-8895.

30. Park GT, Kim HY, Kim EK, Yang JM. Autocrine extracellular signal-regulated kinase activation in normal human keratinocytes is not interrupted by calcium triggering and is involved in the control of cell cycle at the early stage of calcium-induced differentiation. J Korean Med Sci 2007; 22: 290-297.

31. Takei N, Kawamura M, Ishizuka Y, Kakiya N, Inamura N, Namba $\mathrm{H}$ et al. Brain-derived neurotrophic factor enhances the basal rate of protein synthesis by increasing active eukaryotic elongation factor 2 levels and promoting translation elongation in cortical neurons. J Biol Chem 2009; 284: 26340-26348.

32. Swerdlow NR, Braff DL, Geyer MA. Animal models of deficient sensorimotor gating: what we know, what we think we know, and what we hope to know soon. Behav Pharmacol 2000; 11: 185-204.

33. Zhang WN, Murphy CA, Feldon J. Behavioural and cardiovascular responses during latent inhibition of conditioned fear: measurement by telemetry and conditioned freezing. Behav Brain Res 2004; 154: 199-209.

34. Mameli-Engvall M, Evrard A, Pons S, Maskos U, Svensson TH, Changeux JP et al. Hierarchical control of dopamine neuron-firing patterns by nicotinic receptors. Neuron 2006; 50: 911-921.

35. Ungless MA, Grace AA. Are you or aren't you? Challenges associated with physiologically identifying dopamine neurons. Trends Neurosci 2012; 35: 422-430.

36. Grace AA, Bunney BS. The control of firing pattern in nigral dopamine neurons: burst firing. J Neurosci 1984; 4: 2877-2890.

37. Tsuda N, Mizuno M, Yamanaka T, Komurasaki T, Yoshimoto M, Nawa H. Common behavioral influences of the ErbB1 ligands transforming growth factor alpha and epiregulin administered to mouse neonates. Brain Dev 2008; 30: 533-543.

38. Mizuno M, Malta RS Jr, Nagano T, Nawa H. Conditioned place preference and locomotor sensitization after repeated administration of cocaine or methamphetamine in rats treated with epidermal growth factor during the neonatal period. Ann NY Acad Sci 2004; 1025: 612-618.

39. Mizuno M, Kawamura $\mathrm{H}$, Takei $\mathrm{N}$, Nawa $\mathrm{H}$. The anthraquinone derivative emodin ameliorates neurobehavioral deficits of a rodent model for schizophrenia. J Neural Transm 2008; 115: 521-530.

40. Fry DW. Site-directed irreversible inhibitors of the erbB family of receptor tyrosine kinases as novel chemotherapeutic agents for cancer. Anticancer Drug Des 2000; 15: 3-16.

41. Sridhar SS, Seymour L, Shepherd FA. Inhibitors of epidermal-growth-factor receptors: a review of clinical research with a focus on non-small-cell lung cancer. Lancet Oncol 2003; 4: 397-406.

42. McKillop D, Partridge EA, Kemp JV, Spence MP, Kendrew J, Barnett S et al. Tumor penetration of gefitinib (Iressa), an epidermal growth factor receptor tyrosine kinase inhibitor. Mol Cancer Ther 2005; 4: 641-649.

43. Sotoyama H, Zheng Y, Iwakura Y, Mizuno M, Aizawa M, Shcherbakova K et al. Pallidal hyperdopaminergic innervation underlying $D 2$ receptor-dependent behavioral deficits in the schizophrenia animal model established by EGF. PLOS ONE 2011; 6: e25831.

44. Weiner I, Arad M. Using the pharmacology of latent inhibition to model domains of pathology in schizophrenia and their treatment. Behav Brain Res 2009; 204: 369-386. 
45. Kodsi MH, Swerdlow NR. Prepulse inhibition in the rat is regulated by ventral and caudodorsal striato-pallidal circuitry. Behav Neurosci 1995; 109: 912-928.

46. Sotoyama H, Namba H, Takei N, Nawa H. Neonatal exposure to epidermal growth facto induces dopamine D2-like receptor supersensitivity in adult sensorimotor gating. Psychopharmacology (Berl) 2007; 191: 783-792.

47. Arai S, Takuma K, Mizoguchi H, Ibi D, Nagai T, Takahashi $\mathrm{K}$ et al. Involvement of pallidotegmental neurons in methamphetamine- and MK-801-induced impairment of prepulse inhibition of the acoustic startle reflex in mice: reversal by GABAB receptor agonist baclofen. Neuropsychopharmacology 2008; 33: 3164-3175.

48. Bauer S, Kerr BJ, Patterson PH. The neuropoietic cytokine family in development, plasticity, disease and injury. Nat Rev Neurosci 2007; 8: 221-232.

49. Arguello PA, Gogos JA. Modeling madness in mice: one piece at a time. Neuron 2006; 52 : 179-196.

50. Meyer U, Feldon J. Prenatal exposure to infection: a primary mechanism for abnorma dopaminergic development in schizophrenia. Psychopharmacology (Berl) 2009; 206: 587-602.

51. Sotoyama $\mathrm{H}, \mathrm{Namba} \mathrm{H}$, Chiken $\mathrm{S}$, Nambu $\mathrm{A}$, Nawa $\mathrm{H}$. Abnormal hyperactivity of pallidal GABA neurons in the schizophrenia animal model established by the cytokine EGF exposure. J Neurochem 2013; doi:10.1111/jnc.12223.

52. Morrison PD, Murray RM. From real-world events to psychosis: the emerging neuropharmacology of delusions. Schizophr Bull 2009; 35: 668-674.
53. Pan $B$, Huang XF, Deng C. Antipsychotic treatment and neuregulin-1-ErbB4 signalling in schizophrenia. Prog Neuropsychopharmacol Biol Psychiatr 2011; 35: 924-930.

54. Wang XD, Su YA, Guo CM, Yang Y, Si TM. Chronic antipsychotic drug administration alters the expression of neuregulin 1b, ErbB2, ErbB3, and ErbB4 in the rat prefrontal cortex and hippocampus. Int J Neuropsychopharmacol 2008; 11: 553-556.

55. Pan B, Huang XF, Hu CH, Han M, Deng C. Effects of typical and atypical antipsychotics on the expressions of neuregulin 1 and ErbB4 receptors. Aust New Zealand J Psychiatry 2010; 44(Suppl.1): A49.

56. Pereira A, Fink G, Sundram S. Clozapine-induced ERK1 and ERK2 signaling in prefrontal cortex is mediated by the EGF receptor. J Mol Neurosci 2009; 39: 185-198.

57. Melamed E, Durst R, Frucht Y, Globus M. Differential effect of acute and chronic haloperidol administration on dopamine turnover in rat nigrostriatal and retinal dopaminergic neurons. Eur J Pharmacol 1983; 89: 279-282.

(c) (i) (2) Translational Psychiatry is an open-access journal By ${ }_{\mathrm{BS}} \mathrm{SA}$ published by Nature Publishing Group. This work is licensed under a Creative Commons Attribution-NonCommercialShareAlike 3.0 Unported License. To view a copy of this license, visit http://creativecommons.org/licenses/by-nc-sa/3.0/

Supplementary Information accompanies the paper on the Translational Psychiatry website (http://www.nature.com/tp) 